\title{
Misorientation effect of grain boundary on the formation of discontinuous precipitation in second and third generation single crystal superalloys
}

\author{
Zhengrong $\mathrm{Yu}^{1}$, Xianfei Ding ${ }^{1}$, Yunrong Zheng ${ }^{1}$, Lamei $\mathrm{Cao}^{2}$, and Qiang Feng ${ }^{1, \text { a }}$ \\ ${ }^{1}$ National Centre for Materials Service Safety, University of Science and Technology Beijing, Beijing 100083, China \\ ${ }^{2}$ Science and Technology on Advanced High Temperature Structural Material Laboratory, Beijing Institute of \\ Aeronautical Materials, Beijing 100095, China
}

\begin{abstract}
Ni-based single crystal superalloys CMSX-4 and DD10 have been prepared by self-diffusion bonding. The microstructural stability of $0 \sim 30^{\circ}$ artificial grain boundaries have been investigated after heat treatment at $1100^{\circ} \mathrm{C}$ for $0 \sim 300 \mathrm{~h}$. TCP phases and cellular colony developed on boundaries are related to misorientation angle of the bonded boundaries of DD10 and DD10 alloys as well as the bonded boundaries of CMSX-4 and DD10 alloys. The heterogeneous nucleation of TCP phase, enveloped by $\gamma^{\prime}$ film, occurred along $15^{\circ}$ and $20^{\circ}$ boundaries. Discontinuous Precipitation (DP) reaction occurred along high misorientation angle $\left(20^{\circ} \sim 30^{\circ}\right)$ boundaries. However, no TCP phase formation existed along grain boundaries with different misorientation angles in CMSX-4/CMSX-4 bonded alloys as well as for a $0^{\circ}$ boundary in DD10/DD10 and CMSX-4/DD10 bonded alloys. The current study clearly suggests that grain boundary precipitation and its morphology were influenced by the misorientation angle of grain boundary and the content of refractory elements in alloy.
\end{abstract}

\section{Introduction}

Ni-based single crystal superalloys are primary materials for high pressure turbine blades in advanced aircraft engines. The manufacture of multilateral component or hybrid component turbine blades has become attractive for industrial application, recently [1-3]. Fusion welding and diffusion welding techniques are used to produce these multi-component blades. The welding boundary with misorientation angle is similar to grain boundaries [4]. These boundaries are preferential heterogeneous nucleation sites for precipitates due to their high diffusion mobility, and the corresponding mechanical properties of materials and components would be affected [5-7]. To date, research on microstructure stability of boundaries with certain misorientation angle at service temperature is still limited.

Grain boundary precipitation has been classified as continuous precipitation (CP) and discontinuous precipitation (DP) by Geisler [8] and Newkirk [5]. In Ni-base superalloys, TCP phases preferentially precipitate at grain boundaries instead of the matrix due to high diffusion mobility of refractory alloying elements along the boundaries. DP transformation is one type of microstructural instability of a grain boundary, it transforms $\gamma-\gamma^{\prime}$ two-phase microstructure into $\gamma-\gamma^{\prime}+$ TCP lamellar structure in Ni-based superalloys. The occurrence of DP on grain boundaries in Re-containing single crystal superalloys were reported in several studies [9-14]. DP transformation depletes the strengthening elements $\mathrm{Re}$

${ }^{a}$ Corresponding author: qfeng@skl.ustb.edu.cn and $\mathrm{W}$ in the $\gamma$ matrix, resulting in microstructural and property degradation. Limited studies indicated that DP initiation was linked to grain boundary misorientation as well as supersaturation of refractory alloying elements in an alloy $[12,14]$. Grain boundary misorientation had significant effects on grain boundary energy and migration [15]. It was reported that DP occurred at grain boundaries with high misorientation angles while only heterogeneous precipitation of TCP phase occurred along low angle grain boundaries [16]. These results are helpful to understand the misorientation effect on grain boundary precipitation. However, the pertinent research of alloy chemistry and misorientation effect of grain boundary on localized precipitation and DP transformation along grain boundary is still limited.

The present study is to investigate microstructural stability of diffusion bonded boundaries in $2^{\text {nd }}$ and $3^{\text {rd }}$ generation single crystal superalloys. The influence of alloy chemistry and misorientation angle of grain boundary has been focused on TCP phase precipitation and DP transformation along grain boundary. The current study will be helpful for understanding the microstructural stability of single crystal blades containing low angle boundary and the stability of boundary between mutimaterial blades.

\section{Experimental}

The two investigated alloys were a 2nd and 3rd generation Ni-based single crystal superalloys CMSX-4 and DD10, respectively. Their nominal compositions are given in

This is an Open Access article distributed under the terms of the Creative Commons Attribution License 4.0, which permits unrestricted use, distribution, and reproduction in any medium, provided the original work is properly cited. 
Table 1. Nominal compositions of CMSX-4 and DD10 single crystal superalloys (wt.\%).

\begin{tabular}{|l|c|c|c|c|c|c|c|c|c|c|c|}
\hline Alloys & $\mathrm{Cr}$ & $\mathrm{Co}$ & $\mathrm{Mo}$ & $\mathrm{W}$ & $\mathrm{Ta}$ & $\mathrm{Re}$ & $\mathrm{Al}$ & $\mathrm{Ti}$ & $\mathrm{Hf}$ & $\mathrm{C}$ & $\mathrm{Ni}$ \\
\hline CMSX-4 & 6.5 & 9.0 & 0.6 & 6.0 & 6.5 & 3.0 & 5.6 & 1.0 & 0.1 & - & Bal. \\
\hline DD10 & 4.0 & 12.0 & 2.0 & 6.0 & 7.0 & 5.0 & 5.0 & - & 0.15 & 0.02 & Bal. \\
\hline
\end{tabular}

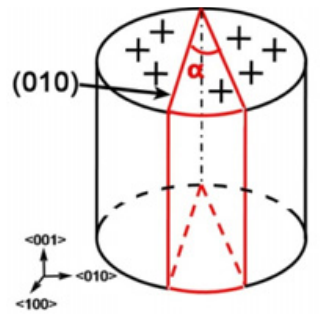

(a)

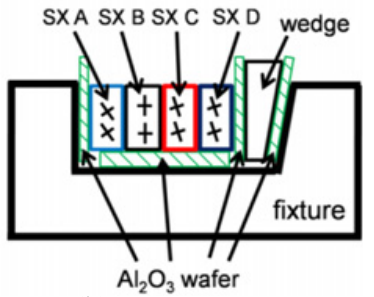

(b)
Figure 1. (a) Schematic diagram of single crystal sector, one of the sectioning planes was (010); (b) schematic diagram of the contacted samples in a fixture.

Table 1. They represent low level and high level Re containing alloys. They were directionally solidified by using the Bridgeman technique. The misorientation between the growth orientation and [001] orientation was less than $5^{\circ}$. CMSX-4 alloy was initially subjected to a solution heat treatment at $1300 \sim 1308^{\circ} \mathrm{C}$ for $8 \mathrm{~h}$, and DD10 alloy was processed by the standard heat treatment [17].

In this study, three types of have been prepared by using the self-diffusion bonding process and they were bonded by DD10 and CMSX-4 alloys. These artificial grain boundaries are termed as DD10/DD10 similar weldment, CMSX-4/CMSX/4 similar weldment and CMSX-4/DD10 dissimilar weldment. Figure $1 \mathrm{a}$ is the schematic diagram of single crystal sector. The (010) plane was set as the base plane of [001] tilt artificial grain boundaries in DD10/DD10 bonded alloys. The misorientation angle was assigned by rotating around [001] from (010) for a certain degree $\alpha$, shown in Fig. 1a. CMSX-4/DD10 boundaries were [001] tilt boundary and (010) plane was the symmetrical plane in order to ensure the bonding surface in the same crystallography condition. The surfaces of bonding planes were polished with 400 through 2000 grit papers. Figure $1 \mathrm{~b}$ is a schematic diagram of the contacted samples in a fixture. The sectioning planes of single crystal samples were held together tightly and were put in a superalloy fixture after ultrasonically cleaned in acetone for 15 mins, as shown in Fig. 1b. A superalloy wedge was inserted into the fixture to make these sectioning surfaces contact intimately. $\mathrm{Al}_{2} \mathrm{O}_{3}$ wafers were inserted into non-bonding surface to avoid bonding at high temperature.

The samples in the fixture were heated at $1290^{\circ} \mathrm{C}$ for $12 \mathrm{~h}$ in a vacuum furnace with $10^{-3} \mathrm{~Pa}$ and then furnace cooled. The X-ray back-scattering Laue method was used to measure the misorientation angle of boundaries. The error range for the target misorientation angle was less than $2^{\circ}$. The bonded samples were heat treated at $1100^{\circ} \mathrm{C}$ for $0 \sim 200 \mathrm{~h}$, and air cooled. Samples were sliced along (001) surface and prepared by using standard metallographic techniques and etched by using a solution of 1 pct HF, 33 pet $\mathrm{CH}_{3} \mathrm{COOH}, 33$ pet $\mathrm{HNO}_{3}$, and 33 pet $\mathrm{H}_{2} \mathrm{O}$.
The microstructure of artificial grain boundaries were characterized by a Zeiss Supra 55 field-emission scanning electron microscope (FE-SEM). The growth direction and orientation change after DP transformation was verified by a TSL-OIM electron back-scattered diffraction (EBSD) analyzer attached to the SEM. The average width of a DP colony along an artificial grain boundary equals to the total area of DP colony divided by length of DP colony, which was measured using Adobe Photoshop CS5 software. To obtain statistically significant results of the average width of continuous DP colonies, $2 \mathrm{~mm}$ in length of DP colony were measured.

\section{Results}

\subsection{Microstructure evolution of artificial grain boundaries}

Figure $2 \mathrm{a}$ is the typical microstructure of $0^{\circ}$ boundary just before heat treatment at $1100^{\circ} \mathrm{C}(0 \mathrm{~h})$ in DD10/DD10 alloys. The fine and irregular $\gamma^{\prime}$ phase precipitated in the matrix during furnace cooling after heat treatment at $1290{ }^{\circ} \mathrm{C}$ for $12 \mathrm{~h}$ in a vacuum furnace. The boundary can be hardly distinguished from the matrix of DD10 alloy. Figures $2 \mathrm{~b}$ and $2 \mathrm{c}$ show the microstructure of $0^{\circ}$ boundary after heat treatment for $50 \mathrm{~h}$ and $200 \mathrm{~h}$, respectively. The $\gamma^{\prime}$ phase in the matrix changed to be cuboidal (Fig. 2b) and it showed coarsening, coalescence and rafting near the boundary with increasing heating time (Fig. 2c). A narrow zone of larger and irregular $\gamma^{\prime}$ precipitates indicates marks the $0^{\circ}$ boundary.

Figures $2 \mathrm{~d}$ to $\mathrm{f}$ show the microstructure of $15^{\circ}$ boundaries in DD10/DD10 alloys after heat treatment at $1100{ }^{\circ} \mathrm{C}$ for $0 \mathrm{~h}, 50 \mathrm{~h}$ and $200 \mathrm{~h}$, respectively. A chain of relatively large $\gamma^{\prime}$ phase is the indication of boundary after the bonding process (Fig. 2d). It is interesting to note that an amount of granular TCP phase precipitated along $15^{\circ}$ boundary, which was enveloped by a $\gamma^{\prime}$ film, after heat treatment for $50 \mathrm{~h}$ (Fig. 2e). Figure $2 \mathrm{f}$ illustrates the size of TCP phase. The average width of $\gamma^{\prime}$ film along $15^{\circ}$ boundary was increased by increasing the heating time.

The typical microstructure of $25^{\circ}$ boundary in DD10/DD10 bonded alloys after heat treatment at $1100^{\circ} \mathrm{C}$ for $0 \mathrm{~h}, 50 \mathrm{~h}$ and $200 \mathrm{~h}$ are shown in Figs. $2 \mathrm{~g}$ to i. Figure $2 \mathrm{~g}$ exhibits that the $25^{\circ}$ boundary was also distinguishable from the matrix due to relatively larger $\gamma^{\prime}$ phase on boundary just after bonding, similar to $15^{\circ}$ boundary (Fig. 2d). However, unlike low angle boundaries, the cellular structure was observed along $25^{\circ}$ boundary after heat treatment at $1100^{\circ} \mathrm{C}$ for $50 \mathrm{~h}$, as shown in Fig. $2 \mathrm{~h}$. It is clearly suggested that the fine $\gamma+\gamma^{\prime}$ microstructure transformed into $\gamma+\gamma^{\prime}+\mathrm{TCP}$ cellular structure as the DP reaction during heat treatment. Figure $2 \mathrm{i}$ indicates the size of TCP phase. Also, the average width of cellular colony 


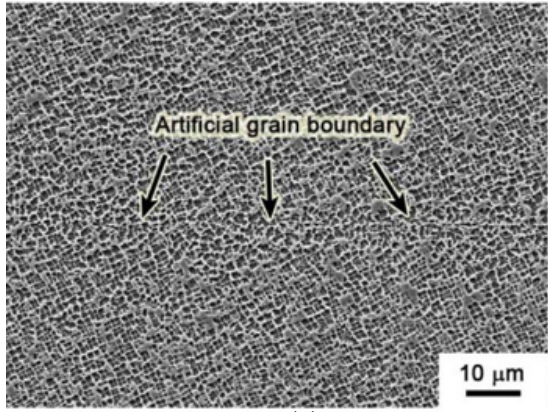

(a)

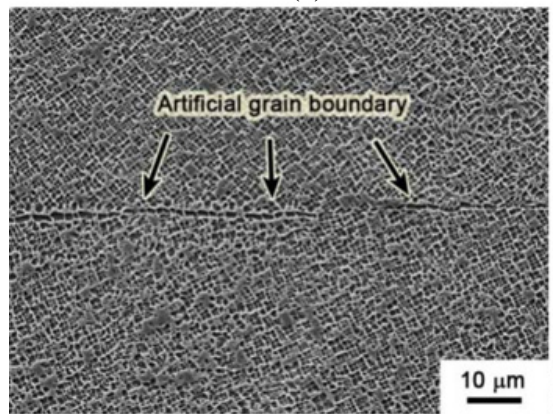

(d)

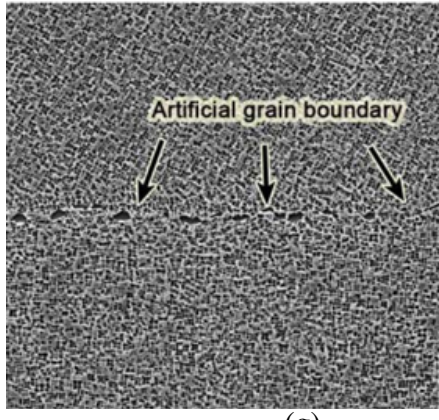

(g)

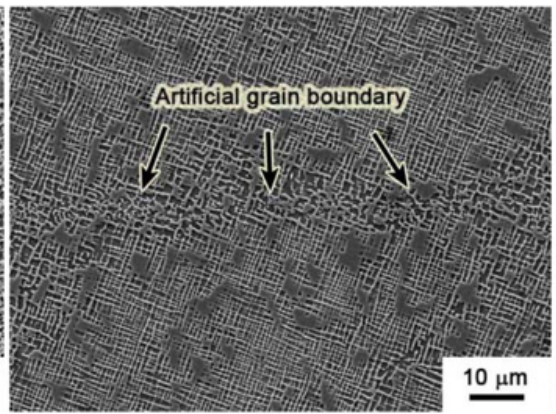

(b)

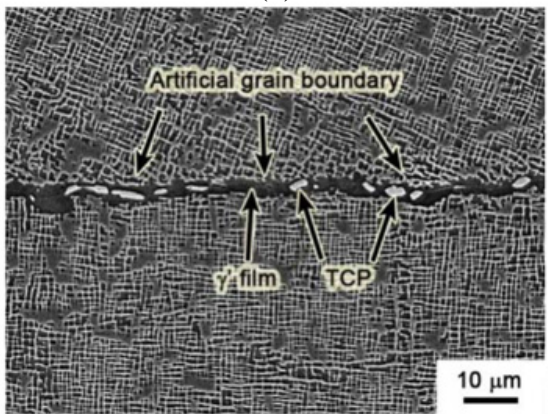

(e)

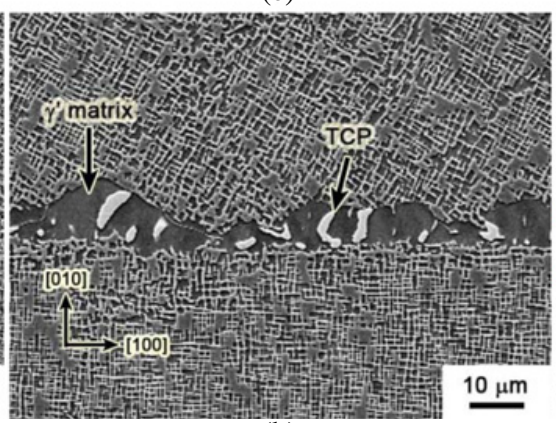

(h)

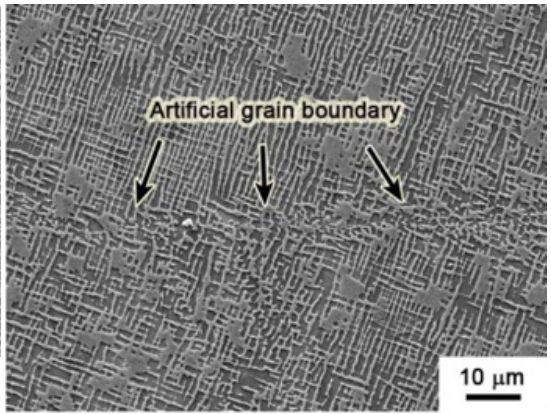

(c)

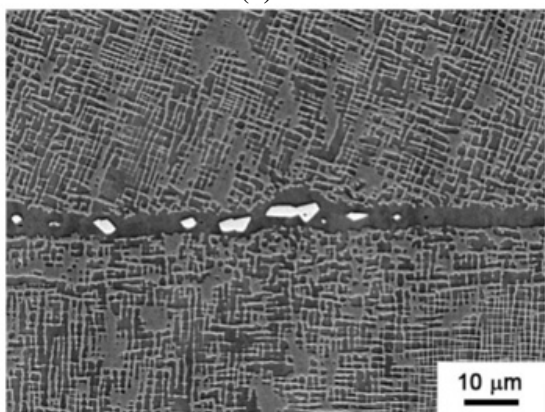

(f)

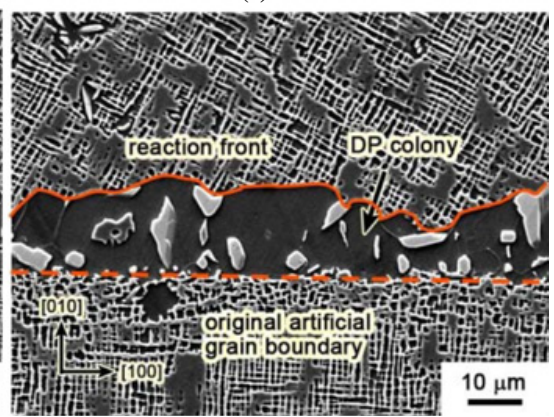

(i)

Figure 2. Typical microsturcture near grain boundaries with different misorientation angles in DD10/DD10 bonded alloys after heat treatment at $1100^{\circ} \mathrm{C}$ for $0 \sim 200 \mathrm{~h}$. (a) $0^{\circ}, 0 \mathrm{~h}$; (b) $0^{\circ}, 50 \mathrm{~h}$; (c) $0^{\circ}, 200 \mathrm{~h}$; (d) $15^{\circ}, 0 \mathrm{~h}$; (e) $15^{\circ}, 50 \mathrm{~h}$; (f) $15^{\circ}, 200 \mathrm{~h}$; (g) $25^{\circ}, 0 \mathrm{~h}$; (h) $25^{\circ}$, $50 \mathrm{~h}$; (i) $25^{\circ}, 200 \mathrm{~h}$.

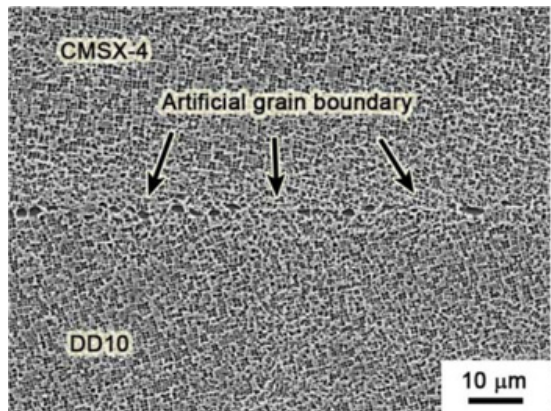

(a)

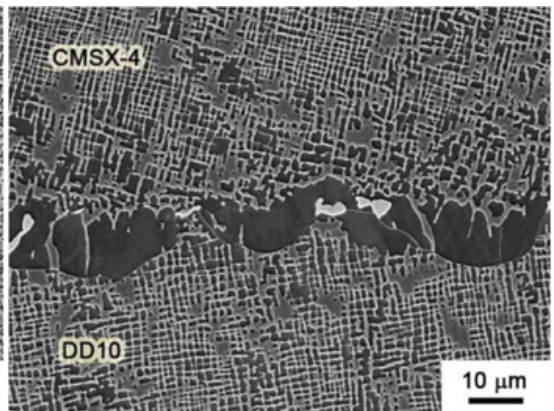

(b)

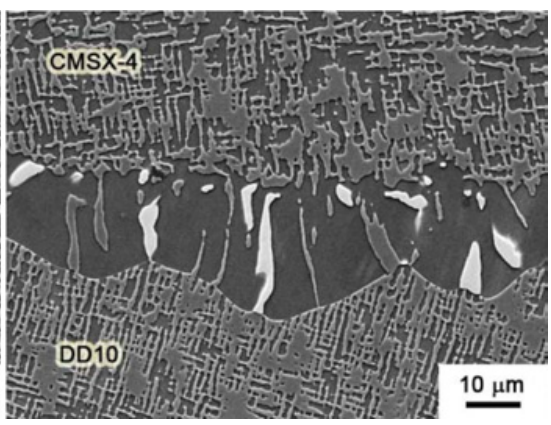

(c)

Figure 3. Typical microsturcture near $25^{\circ}$ boundaries in CMSX-4/DD10 bonded alloys after heat treatment at $1100{ }^{\circ} \mathrm{C}$ for $0 \sim 200 \mathrm{~h}$. (a) $0 \mathrm{~h}$; (b) $100 \mathrm{~h}$; (c) $200 \mathrm{~h}$.

along $25^{\circ}$ boundary increased with increasing the heating time. It should be noted that the granular TCP precipitates existed along the original boundary and the lamellar TCP phase grew with the curved moving reaction front away from the original boundary, which was nearly flat and normal to the [010] orientation (Figs. $2 \mathrm{~h}$ and 2i). It is suggested that the cellular colony grew from the grain with the boundary normal to (010) plane into another grain, and it was also a [001] tilt boundary, deviating from (010) plane for $25^{\circ}$.

The CMSX-4/CMSX-4 and CMSX-4/DD10 bonded alloys with $25^{\circ}$ boundaries were also investigated after heat treatment at $1100{ }^{\circ} \mathrm{C}$ for $0 \sim 200 \mathrm{~h}$. The typical microstructure along $25^{\circ}$ boundaries in CMSX-4/ CMSX-4 bonded alloys was $\gamma+\gamma^{\prime}$ microstructure with neither TCP precipitates nor cellular colonies during the 


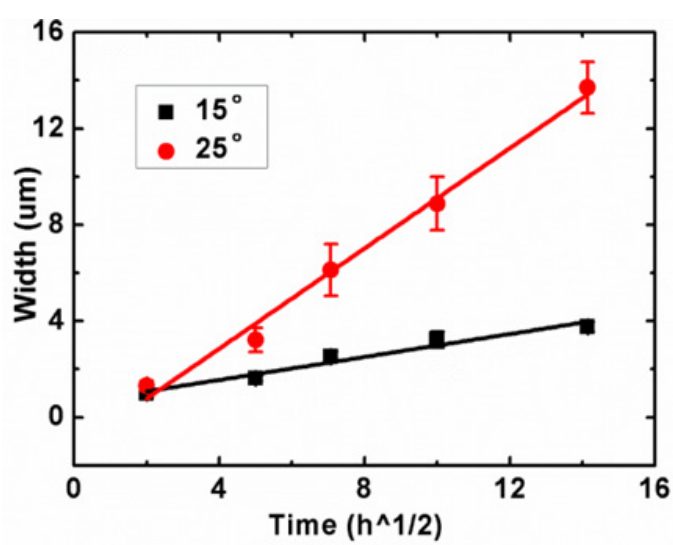

Figure 4. Average widths of $\gamma^{\prime}$ film along $15^{\circ}$ boundary and the cellular colony along $25^{\circ}$ boundary as a function of time after heat treatment at $1100^{\circ} \mathrm{C}$ in DD10/DD10 bonded alloys.

whole heat treatment (images not shown). Figure 3 shows that the typical microstructural features of $25^{\circ}$ boundary in CMSX-4/DD10 bonded alloys were quite similar to those of DD10/DD10 bonded alloys during heat treatment (Figs. 3g-i). As expected, the formation of the cellular colony with $\gamma+\gamma^{\prime}+\mathrm{TCP}$ lamellar structure occurred along CMSX-4/DD10 boundary. It is noteworthy that the reaction front of the cellular structure was primarily migrated into the DD10 alloy.

Figure 4 shows the average widths of $\gamma^{\prime}$ film and cellular colony along 15 and $25^{\circ}$ boundaries in DD10/DD10 bonded alloys after heating at $1100^{\circ} \mathrm{C}$ as a function of time. The current results indicate that a linear relationship exists between the average width and the squared root of heating time, but the linear slopes were significantly different for two different boundaries.

\subsection{Composition of phases in DP zone and matrix}

Table 2 lists the compositions of TCP, $\gamma$ and $\gamma^{\prime}$ phases within the cellular colony and the matrix in DD10/DD10 bonded alloys after heating at $1100^{\circ} \mathrm{C}$ for $200 \mathrm{~h}$. The cellular TCP phase was significantly enriched in $\mathrm{W}$ and Re. The Re contents of $\gamma$ and $\gamma^{\prime}$ phases in the matrix were higher than those in the cellular colony. These results are consistent with previous studies $[9,16]$.

\subsection{Orientation change of DP transformation}

Figures $5 \mathrm{a}$ and $5 \mathrm{c}$ show the microstructure of $20^{\circ}$ and $30^{\circ}$ boundary in DD10/DD10 bonded alloys after heat treatment at $1100^{\circ} \mathrm{C}$ for $300 \mathrm{~h}$, which are similar to $15^{\circ}$ and $25^{\circ}$ boundary, respectively. Again, their typical microstructural features are $\gamma^{\prime}$ film along the boundary and $\gamma+\gamma^{\prime}+$ TCP cellular colony, respectively. Figure $5 \mathrm{~b}$ is the corresponding orientation map of Fig. 5a, illustrating that the original artificial grain boundary did not migrate at $20^{\circ}$ boundary. The orientation map of $30^{\circ}$ boundary shown in Fig. 5d indicates that the original artificial grain boundary migrated under the heat treatment process. The migration direction of cellular colony boundary primarily deviated from the original artificial grain boundary. Meanwhile, the orientation of the cellular colony had the same orientation as the grain with the original artificial grain boundary normal to (010) plane.

\section{Discussions}

Instead of the formation of precipitates at random within the alloy matrix, nuclei of new phases form preferentially at grain boundaries due to interfacial nucleation sites as well as their high diffusion mobility. Localized precipitation occurs at the grain boundary in earlier stage of $\mathrm{CP}$, and then the precipitates grow along the grain boundary during the extended heat treatment [18]. DP transformation is the combination of heterogeneous precipitation and grain boundary migration. Across the reaction front, there is a discontinuous change in both orientation and solute concentration [19]. DP initiation is linked to grain boundary energy and supersaturation of refractory elements in the alloy $[9,16]$.

It is well known that the formation of TCP phases and DP reaction is closely associated with the content of refractory alloying elements. TCP phases are composed principally of the elements $\mathrm{Cr}, \mathrm{Mo}, \mathrm{Co}, \mathrm{W}$ and $\mathrm{Re}$, and these elements are most effective at conferring resistance to creep [20]. In order to improve the creep resistance, $5 \sim 6$ wt. $\%$ Re is usually added to 3rd generation single crystal superalloys compared with 2 nd generation single crystal superalloys containing about $3 \mathrm{wt} \%$ Re [20]. In this study, no TCP precipitates existed on different boundaries in the 2nd generation single crystal alloy CMSX-4 after heat treatment at $1100^{\circ} \mathrm{C}$ for $0 \sim 200 \mathrm{~h}$ (images not shown). However, both $\mathrm{CP}$ and DP transformation were observed on boundaries in DD10/DD10 and CMSX4/DD10 bonded alloys (Figs. 2e-2i, 3b and 3c). It should be noted that the DP reaction front of CMSX-4/DD10 boundary primarily migrated into the DD10 alloy (Figs. 3b and $3 \mathrm{c}$ ). The current results indicate that Re content plays an important role in CP and DP transformation. Supersaturation of Re in the matrix is the driving force for heterogeneous nucleation of TCP phases and DP transformation in boundary precipitation [5]. High Re content in DD10 alloy is closely related to the migration direction of DP reaction front along CMSX-4/DD10 boundaries.

Misorientation of grain boundary is another important factor to influence the precipitate formation and grain boundary migration [19]. Both grain boundary energy and migration rate are associated with the misorientation angle of grain boundary [6]. In the fcc Al, the relative grain boundary energy of [100] tilt boundaries with $15 \sim 30^{\circ}$ misorientation angles were approximately equal $[15,21]$. However, there was a rapid increase in the migration rate of grain boundary at about $15 \sim 20^{\circ}$ misorientation angles [15]. Heterogeneous nucleation of TCP phases was observed at $8^{\circ}$ grain boundary in a $3^{\text {rd }}$ generation single crystal superalloy containing $6.3 \mathrm{wt} . \%$ $\mathrm{Re}$ in a previous study [14], while the growth of cellular colony was detected on grain boundaries that were misoriented by $14^{\circ}$. Walston [8] suggested higher misorientation angle of grain boundaries were required for DP transformation in more stable alloys. In the current investigation, granular TCP phases enveloped 
Table 2. Composition of $\gamma, \gamma^{\prime}$ and TCP phases within the cellular colony (CC) and matrix at $25^{\circ}$ boundaries in DD10/DD10 bonded alloy after heat treatment at $1100{ }^{\circ} \mathrm{C}$ for $100 \mathrm{~h}$ (wt. \%).

\begin{tabular}{|l|c|c|c|c|c|c|c|c|}
\hline phase & $\mathrm{Al}$ & $\mathrm{Cr}$ & $\mathrm{Co}$ & $\mathrm{Ni}$ & $\mathrm{Mo}$ & $\mathrm{Ta}$ & $\mathrm{W}$ & $\mathrm{Re}$ \\
\hline $\mathrm{TCP}$ in CC & 0.00 & 5.06 & 10.15 & 9.63 & 6.59 & 3.55 & 24.01 & 41.02 \\
\hline$\gamma^{\prime}$ in CC & 8.48 & 1.73 & 9.38 & 57.59 & 1.34 & 12.67 & 7.14 & 1.69 \\
\hline$\gamma$ in CC & 6.10 & 5.48 & 17.24 & 54.54 & 3.24 & 1.40 & 5.39 & 5.34 \\
\hline$\gamma^{\prime}$ in matrix & 10.09 & 2.49 & 11.64 & 58.11 & 1.43 & 9.15 & 2.86 & 4.24 \\
\hline$\gamma$ in matrix & 5.96 & 4.78 & 14.59 & 49.45 & 2.95 & 4.85 & 8.18 & 9.25 \\
\hline
\end{tabular}
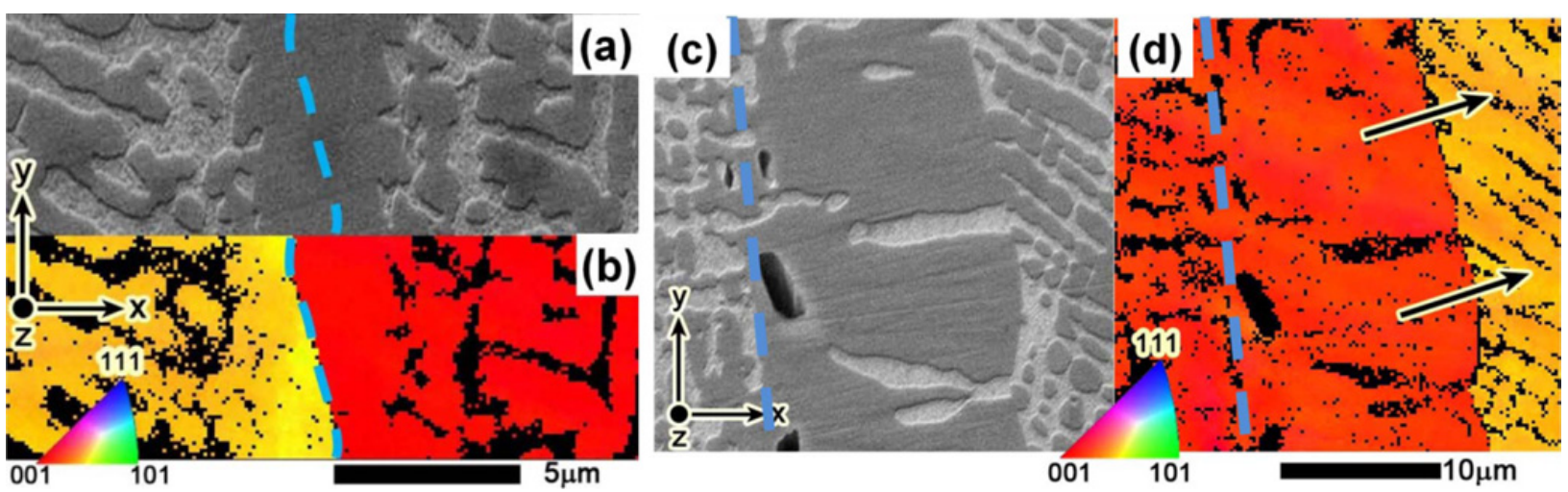

Figure 5. SEM and EBSD images (x direction IPF) of two different boundaries in DD10/DD10 bonded alloys after heat treatment at $1100^{\circ} \mathrm{C}$ for $300 \mathrm{~h}$. (a) $20^{\circ}$, SEM image; (b) $20^{\circ}$, EBSD image; (c) $30^{\circ}$, SEM image; (d) $30^{\circ}$, EBSD image.

by $\gamma^{\prime}$ film precipitated along $15^{\circ}$ and $20^{\circ}$ boundaries (Figs. 2e, 2f and Fig. 5a) after heat treatment at $1100^{\circ} \mathrm{C}$ for $200 \sim 300 \mathrm{~h}$, while the cellular colony developed on $25^{\circ}$ and $30^{\circ}$ boundaries of DD10/DD10 alloys (Figs. 2h, $2 \mathrm{i}$ and Fig. 5c) at the same heat treatment condition. No boundary migration and no orientation change occurred at $20^{\circ}$ boundaries after TCP phase formation, while the DP transformation and the orientation change happened at $30^{\circ}$ boundaries of DD10/DD10 alloys, illustrated by the EBSD maps (Fig. 5). The current results clearly suggest that localized precipitation of TCP phases occurred along grain boundaries with a misorientation angle less than $20^{\circ}$, but the DP transformation existed along boundaries with the misorientation angle larger than $20^{\circ}$ after heat treatment at $1100^{\circ} \mathrm{C}$ for $200 \sim 300 \mathrm{~h}$. One of the driving forces for TCP phase formation along grain boundary in both CP and DP transformation is grain boundary energy associated with misorientation angle. Howeverthe growth of cellular colony required high grain boundary migration after the TCP phases nucleated on boundaries. The high grain boundary migration merely supplied by 25 and $30^{\circ}$ boundaries. Therefore, the misorientation angle of grain boundary for DP transformation in the current DD10 alloy was clearly higher than $14^{\circ}$ as shown in the previous study [16]. The lower Re content in the DD10 alloy (5.0 wt.\%) may be the main reason of higher threshold of misorientation value for DP reaction.

The DP growth rate in Ni-based superalloys was considered to be controlled by volume diffusion of high refractory elements [12,22,23]. Walston [12] and Matsuoka [24] investigated secondary reaction zones and determined their diffusion coefficients from the slope of d$\mathrm{t}^{1 / 2}$ (d: the average width of SRZ zone; $\mathrm{t}$ : heat treatment time). The calculated diffusion coefficients had the same order as $\mathrm{Al}$ diffusion in $\mathrm{Ni}[25,26]$. They suggested that the SRZ growth was controlled by $\mathrm{Al}$ diffusion from coating to substrate. In this study, the diffusion coefficient at $25^{\circ}$ boundary of DD10/DD10 alloys which calculated from the slope of the $\mathrm{d}-\mathrm{t}^{1 / 2}$ plot in Fig. 4 is $3.02 \times$ $10^{-16} \mathrm{~m}^{2} / \mathrm{s}$. The diffusion coefficients of $\mathrm{W}$ and $\mathrm{Re}$ in $\mathrm{Ni}$ at $1100{ }^{\circ} \mathrm{C}$ were reported by Karunaratne and Reed [27] to be $6.67 \times 10^{-16} \mathrm{~m}^{2} / \mathrm{s}$ and $1.40 \times 10^{-16} \mathrm{~m}^{2} / \mathrm{s}$, respectively. The diffusion coefficient in the current study is in between them. The results illustrated that the growth rate of the cellular colony was controlled by the diffusion of $\mathrm{Re}$ and $\mathrm{W}$.

Grain boundary migration was affected by crystal anisotropy [28]. Anisotropy of SRZ formation in aluminized Ni-based single crystal superalloys has been investigated by Murakami [29]. SRZ was not formed along the $\{001\}\langle 100\rangle$ directions in TMS-75 alloy, and greatly enhanced SRZ was formed along the $\{001\}\langle 110\rangle$ directions. In the current study, the growth of cellular colony significantly deviated from (010) plane into another grained as shown in Fig. 5d. The results indicate the tendency of DP formation on (010) was lower than for another orientation. The preference of DP formation was similar to previous research [29], and suggested that DP formation on DD10/DD10 boundaries was anisotropic.

\section{Conclusions}

A series of artificial grain boundaries in Re-containing CMSX-4 ( $2^{\text {nd }}$ generation single crystal superalloys) and DD10 ( $3^{\text {rd }}$ generation single crystal superalloys) alloys with certain misorientation angles were investigated for microstructural stability of boundaries after heat treatment at $1100{ }^{\circ} \mathrm{C}$ for $0 \sim 300 \mathrm{~h}$. No TCP phase formation existed along grain boundaries with different misorientation angles in CMSX-4/CMSX-4 bonded alloys as well as 
for $0^{\circ}$ boundary in DD10/DD10 and CMSX-4/DD10 bonded alloys. The TCP phase, enveloped by $\gamma^{\prime}$ film, precipitated along $15^{\circ}$ and $20^{\circ}$ boundary in DD10/DD10 bonded alloys without the migration of original artificial grain boundaries; while the DP reaction occurred on $25^{\circ}$ and $30^{\circ}$ boundary in DD10/DD10 and CMSX-4/DD10 bonded alloys, and the cellular colony grew from the grain with the boundary normal to (010) plane into another grain in DD10 alloy. The current study clearly suggests that grain boundary precipitation and its morphology was influenced by the misorientation angle and refractory alloying elements, especially for Re content.

The financial supports provided by National Natural Science Foundation of China (Grant No.: 51071016) and National High Technology Research and Development Program of China (Grant No.: 2012AA03A513) are gratefully acknowledged.

\section{References}

[1] D Godfrey, M Morris, M Menon. Multi-material turbine components. US Patent. 13/360,126 (2013)

[2] J Allister. Hybrid single crystal-powder metallurgy turbine component. US Patent. 10/155,257 (2004)

[3] S Finn, J Schilling, W Lin, et al. Multi-component hybrid turbine blade. US Patent. 6,607,358 (2003)

[4] Z Ruan, Y Zheng. Scripta Mater. 34(1), 163 (1996)

[5] J Newkirk. Precipitation from Solid Solution. 11 (1959)

[6] G Gottstein, L Shvindlerman. Grain Boundary Migration in Metals: Thermodynamics, Kinetics. (2011)

[7] K Yasuda, M Kobayashi, A Okayama, et al. Superalloys 1988. 765-774 (1988)

[8] A Geisler. Phase Trans. Solids, 387 (1951)

[9] A Heckl, S Cenanovic, M Goken, et al. Metal. Mater. Trans. A. 43(1), 10-19 (2012)
[10] A Heckl, S Neumeier, S Cenanovic, et al. Acta Mater. 59(17), 6563-6573 (2011)

[11] A Yeh, S Tin. Metal. Mater. Trans. A. 37(9), 2621-2631 (2006)

[12] W Walston, J Schaeffer, W Murphy. Superalloys 1996. 9-18 (1996)

[13] W Walston, K O'Hara, E Ross, et al. Superalloys 1996. 27-34 (1996)

[14] T Pollock. Mater. Sci. Eng. B. 32, 255-266 (1995)

[15] C Yang, A Rollett, W Mullins. Scripta Mater. 44(12), 2735-2740 (2001)

[16] J Nystrom, T Pollock, W Murphy, et al. Metall. Mater. Trans. A. 28(12), 2443-2452 (1997)

[17] M Xue, Y Zhang. J. Mater. Eng. 1(10), 23-27 (2011)

[18] J Shapiro, J Kirkaldy. Acta Metall. 16(4), 579-585 (1968)

[19] D Williams, E Butler. Int. Metal. Rev. 26(1), 153-183 (1981)

[20] C Rae, R Reed. Acta Mater. 49(19), 4113-4125 (2001)

[21] G Hasson, C Goux. Scripta metal. 5(10), 889-894 (1971)

[22] I Manna, S Pabi, W Gust. Int. Mater. Rev. 46(2), 53-91 (2001)

[23] C Zener. Trans. Aime. 167, 550-595 (1946)

[24] Y Matsuoka, Y Aoki, K Matsumoto, et al. Superalloys 2004. 637-642 (2004)

[25] M Janssen, G Rieck. Metall. Trans. 239, 1372 (1967)

[26] L Larko, et al. Diffusion Procrss in Ordered Alloys. 117 (1981)

[27] M Karunaratne, R Reed. Acta Mater. 51(10), 2905-2919 (2003)

[28] R Schmelzle, B Giakupian, T Muschik, et al. Acta Metal. Mater. 40(5), 997-1007 (1992)

[29] H Murakami, T Sakai. Scripta Mater. 59(4), 428-431 (2008) 